\title{
A RANDOMIZED COMPARATIVE STUDY TO ASSESS THE EFFECT OF INTRATHECAL NALBUPHINE VERSUS INTRATHECAL FENTANYL AS ADJUVANT TO BUPIVACAINE FOR LOWER LIMB ORTHOPAEDIC SURGERY
}

\author{
Debabrata Nath Sharma1, Manmaya Padhy², Monali Kar ${ }^{3}$
}

${ }^{1}$ Associate Professor, Department of Anaesthesiology, MKCG Medical College, Berhampur, Odisha, India.

${ }_{2}^{2}$ Postgraduate Student, Department of Anaesthesiology, MKCG Medical College, Berhampur, Odisha, India.

${ }^{3}$ Postgraduate Student, Department of Community Medicine, MKCG Medical College, Berhampur, Odisha, India.

\section{ABSTRACT}

\section{BACKGROUND}

In lower limb orthopaedic surgery, post-operative pain management is a major issue as spinal anaesthesia provides short duration analgesia. Many adjuvants like opioids are added to prolong the effects of spinal anaesthesia. we wanted to determine the better additive (fentanyl/nalbuphine) for bupivacaine for lower limb orthopaedic surgery by comparing nalbuphine (1 mg) with fentanyl $(25 \mu \mathrm{g})$ as intrathecal adjuvants to $0.5 \%$ hyperbaric bupivacaine in patients undergoing elective lower limb orthopaedic surgery.

\section{MATERIALS AND METHODS}

This study is a double blinded randomized controlled trial conducted at MKCG Medical College, Berhampur from April 2018 to October 2018. Patients scheduled for elective lower limb orthopedic surgery under subarachnoid block were enrolled. Sample size was 30 per group. Intervention (A) group received $3 \mathrm{ml}(15 \mathrm{mg})$ of $0.5 \%$ bupivacaine with $0.5 \mathrm{ml}$ of nalbuphine (1 mg) intrathecally and control (B) group received $3 \mathrm{ml}$ of $0.5 \%$ bupivacaine with $0.5 \mathrm{ml}$ of fentanyl (25 mg). The outcome variables were- onset of sensory and motor blockade, duration of sensory and motor blockade, duration of analgesia, intra-operative hemodynamic changes and adverse effects like sedation, pruritus, nausea and vomiting. Data was analysed with SPSS, and independent sample t test was applied.

\section{RESULTS}

There was no significant difference in onset of sensory and motor blockade between the two groups. Duration of sensory blockade was significantly prolonged (112.6 $\pm 8.3 \mathrm{~min})$ in group A than in group B (103.7 $\pm 7.5 \mathrm{~min})$ and duration of motor block was significantly extended in patients of Group A $(155.7 \pm 16.8 \mathrm{~min})$ than group B $(133.1 \pm 12.4 \mathrm{~min})$. The duration of effective analgesia was significantly more in group A than group B. There was no significant difference in sedation score between two groups. There was no occurrence of intraoperative nausea, vomiting, respiratory depression, shivering or supplemented analgesia.

\section{CONCLUSION}

Nalbuphine (1 mg) as intrathecal adjuvants to $0.5 \%$ hyperbaric bupivacaine increases the duration of sensory block, motor block and the effective analgesia time more efficiently than fentanyl in patients scheduled for elective lower limb orthopedic surgery under subarachnoid block.

\section{KEY WORDS}

Nalbuphine, Randomised Control Trial, Bromage Scale, Bupivacaine, Sensory Regression

HOW TO CITE THIS ARTICLE: Sharma DN, Padhy M, Kar M. A randomized comparative study to assess the effect of intrathecal nalbuphine versus intrathecal fentanyl as adjuvant to bupivacaine for lower limb orthopaedic surgery. J. Evolution Med. Dent. Sci. 2019;8(12):830-834, DOI: 10.14260/jemds/2019/185

\section{BACKGROUND}

Spinal anaesthesia had several advantages over general anaesthesia as it is easy to perform, provide faster onset, reduced stress response to surgery and effective postoperative analgesia. In lower limb orthopaedic surgery postoperative pain management is a major issue because spinal anaesthesia with only local anaesthetics provides analgesia of short duration

'Financial or Other Competing Interest': None.

Submission 03-01-2019, Peer Review 05-03-2019,

Acceptance 12-03-2019, Published 25-03-2019.

Corresponding Author:

Manmaya Padhy,

Shakti Nagar, $3^{\text {rd }}$ Lane Extension,

Lochapada Road, Berhampur,

Odisha, India.

E-mail: manmayapadhy52@gmail.com

DOI: $10.14260 /$ jemds $/ 2019 / 185$

\section{(c) $)(1)(9)$}

For this reason many intrathecal adjuvants are added to local anaesthetics to prolong the effect of spinal anaesthesia. Intrathecal opioids as an adjuvant has gained popularity as it prolongs the duration of post-operative analgesia, reduces the local anaesthetics requirements and improves hemodynamic stability. ${ }^{1}$ Fentanyl, a 4 -anilido-piperidine compound is highly lipid soluble opioid agonist that acts on $\mu$ $\mathrm{(mu}$ ) receptor and principally responsible for supra spinal and spinal analgesia along with side effects like nausea, vomiting, pruritus, sedation and respiratory depression. However various studies have stated that it improves the quality of sensory anaesthesia and extends post-operative analgesia duration.2, 3 Nalbuphine hydrochloride, a synthetic opioid of phenanthrene series acts as a partial kappa receptor agonist and $\mu$ receptor antagonist to provide analgesia. Nalbuphine has been used intrathecally by various investigators to enhance the post-operative analgesia and did not document any reports of neurotoxicity. 4

Nalbuphine is easily available whereas other opioid agonists like morphine, fentanyl are limited and needs 
licensing as they come under Narcotic Act. Some studies compared the effect of intrathecal nalbuphine with intrathecal fentanyl in caesarean section. $.5,6,7$ So the present randomised control trial aimed to find out whether Fentanyl or Nalbuphine is better additive for bupivacaine for the lower limb orthopaedic surgery. The objective of the study is to compare nalbuphine (1 $\mathrm{mg}$ ) with fentanyl as intrathecal adjuvants to $0.5 \%$ hyperbaric bupivacaine in terms of sensory and motor blockade characteristics, duration of postoperative analgesia, intra-operative hemodynamic changes and adverse effects like sedation, pruritus, nausea and vomiting in patients undergoing elective lower limb orthopaedic surgery.

\section{MATERIALS AND METHODS}

The present study is a double blinded randomized controlled trial (parallel trial) conducted at MKCG Medical College, Berhampur from April 2018 to October 2018. Prior to the study ethical approval has been obtained from the ethical committee of MKCG Medical College. Patients scheduled for elective lower limb orthopedic surgery under subarachnoid block at MKCG hospital within the study period were enrolled for the study. Patients of American Society of Anaesthesiologist (ASA) physical status I and II of both genders aged between 18-60 years were included in the study. Patients with significant cardiovascular, renal, hepatic, pulmonary, neurologic, metabolic diseases; obese (BMI > 30 $\mathrm{kg} / \mathrm{m}^{2}$ ) and who were contraindicated for spinal anaesthesia were excluded from the study. In our study total 60 patients (30 in each group) were taken. Sample size was taken for convenience.

The spinal block and intra-operative, post-operative information record were performed by another anaesthesiologist who was blinded to the drugs and groups. All patients included in the study remained nil per oral overnight prior to surgery and received tablet alprazolam $(0.5 \mathrm{mg})$ and tablet ranitidine $(150 \mathrm{mg})$ orally the night before surgery. In the operation theatre after the standard monitor were attached, intravenous access was established with a $18 \mathrm{G}$ cannula and patients were preloaded with 10 $\mathrm{ml} / \mathrm{kg}$ Ringer Lactate solution over 20 minutes. At this point base line pulse rate (PR), non-invasive blood pressures (NIBP), ECG, SpO2 were recorded. Then subarachnoid block was performed in all the patients in sitting position through a midline approach at $\mathrm{L}_{3}-\mathrm{L}_{4}$ intervertebral space using a $25 \mathrm{G}$ Quincke's spinal needle under strict aseptic precaution. After completion of intrathecal injection patients were made to lie supine and the end point of injection was taken as time zero. The vitals (ECG, PR, HR, systolic and diastolic BP, pulse oximetry were monitored and recorded every 5 minutes for 30 minutes and then every 15 minutes till the end of the surgery. Hypotension (fall of systolic BP $<90 \mathrm{~mm} \mathrm{Hg}$ or mean $\mathrm{BP}<20 \%$ from base line) was treated with injection mephentermine (6 mg) I.V. and intravenous fluid. Bradycardia (HR $<60$ beats per minutes) was treated with atropine $(0.6 \mathrm{mg})$ intravenously.

\section{Outcome Measurement}

The outcome variables were onset of sensory and motor blockade, duration of sensory and motor blockade, duration of analgesia, intra-operative hemodynamic changes and adverse effects like sedation, pruritus, nausea and vomiting in patients undergoing elective lower limb orthopaedic surgery. Sensory block level was assessed by loss of pinprick sensation at every 2-minute interval. Onset of sensory block defined as time from injection of intrathecal drug to absence of sensation at T10 level. Duration of sensory block expressed in terms of two-point regression from highest level of sensory blockade was recorded in each patient. Motor block level was assessed by Bromage scale. 8 The scale ranges from 0 to 3 score; score 0 - patient able to move the hip, knee and ankle; score 1-unable to move the hip but is able to move the knee and ankle; score 2-unable to move the hip and knee but is able to move the ankle; score 3- unable to move the hip, knee and ankle. Onset of motor block was the time taken from intrathecal injection to achievement of motor block of Bromage score 3. Duration of motor block was the time required for motor blockade to return to scale 0 . Intra and postoperative pain was assessed on visual analogue scale (VAS- 0 to 10 where 0 means no pain to 10 worst possible pain). Duration of effective analgesia was taken as the time from the completion of spinal injection to the first rescue analgesic requirement i.e. VAS score of $>3$ constituted the end point of the study. Patients with VAS score $>3$ received diclofenac $75 \mathrm{mg}$ intramuscularly for rescue analgesia. Level of sedation assessed by Ramsay Sedation Scale ${ }^{9}$ Score 1Anxious or restless or both, 2- Cooperative, orientated and tranquil, 3- Responding to commands, 4- Brisk response to stimulus, 5- Sluggish response to stimulus, 6- No response to stimulus. Incidence of adverse effects such as nausea, vomiting, pruritus, shivering, respiratory depression recorded by clinical observation. Intraoperative nausea was treated with Ondansetron (4 mg) and any incidence of pruritus was treated with injection Pheniramine maleate $2 \mathrm{ml}$ (45 mg) intravenously. Respiratory depression was defined as respiratory rate $<8$ breaths/min or $\mathrm{SpO}_{2}<94 \%$ on room air and treated with oxygen supplementation or ventilatory support, if required.

\section{Statistical Analysis}

All data were analysed with SPSS (version 16.0). To reduce bias during interpretation randomization code was broken before analysis. To assess the superiority, mean of outcome variables between two groups were analysed. As variables were continuous data independent sample $t$ test was applied to compare the means of outcomes in the two groups and for discrete data chi-square test was applied. In the study P value less than 0.05 was taken as statistically significant.

\section{RESULTS}

The present study compared the clinical efficiency of nalbuphine (1 $\mathrm{mg}$ ) with fentanyl as intrathecal adjuvants to $0.5 \%$ hyperbaric bupivacaine in 60 adult patients scheduled for elective lower limb orthopaedic surgery under subarachnoid block. Outcomes were measured in terms of sensory and motor blockade characteristics, duration of analgesia, intra-operative hemodynamic changes and adverse effects like sedation, pruritus, nausea and vomiting. There was no protocol deviation and all the patients were cooperative with subsequent assessment. There were no surgical or anaesthetic complications.

Baseline characteristics of all patients were depicted in table 1. There was no significant difference between study 
groups regarding mean age, weight, height, gender and duration of surgery. (Table 1)

The time to reach T10 sensory level that is the onset of sensory blockade was $3.2 \pm 0.35 \mathrm{~min}$ in patients of Group A and $3.5 \pm 0.97 \mathrm{~min}$ in patients of Group B with no statistical significance $(\mathrm{P}=0.12)$. Time for two segment sensory regression was significantly prolonged in patients of Group A (112.6 $\pm 8.3 \mathrm{~min}$ ) as compared to patients of Group B (103.7 \pm 7.5 min) with $\mathrm{P}<0.001$. (Table 2 )

The mean time required for the onset of motor block to Bromage grade 3 was $7.67 \pm 12.5$ min in patients of Group A and $8.82 \pm 3.25 \mathrm{~min}$ in patients of Group B, but there was no significant difference between these means. $(P=0.13)$. The mean duration of motor block was significantly extended in patients of Group A (155.7 $\pm 16.8 \mathrm{~min})$ as compared to patients of group B $(133.1 \pm 12.4 \mathrm{~min})$ with $\mathrm{p}$ value as < 0.001 .

The mean duration of effective analgesia was $263.4 \pm 20.8$ min in patients of Group A which was significantly prolonged as compare to patients of Group B (228.7 $\pm 19.8 \mathrm{~min})$ with $\mathrm{P}<$ 0.0001. (Table 2)

The Modified Ramsay sedation score was recorded at 30 min interval from subarachnoid injection till $120 \mathrm{~min}$ and then at 2-hour intervals up to 8 hours. Mean sedation score was higher in Group A (2.10 \pm 0.36$)$ as compared to Group B $(2.02 \pm 0.14)$, but this was not statistically significance. Figure 1 and 2 showed the heart rate (HR) and mean arterial pressure (MAP) in two groups at various time points during intra-operative and post-operative periods. (Figure 1 and 2). Incidence of hypotension and bradycardia during intraoperative period was minimal and did not require any medical intervention. No patient in any group had significant intraoperative hypoxemia ( $\mathrm{SpO} 2<92 \%$ ) and postoperatively, the SpO2 was well maintained above $97 \%$ on air in all patients. There was no occurrence of intraoperative nausea, vomiting, respiratory depression, shivering, and bradycardia among all groups. None of the patient needed supplemented analgesia during surgery.

\begin{tabular}{|c|c|c|c|}
\hline Characteristics & Group A & Group B & p-Value \\
\hline Age (Year) & $45.5 \pm 2.3$ & $46.7 \pm 3.9$ & 0.15 \\
\hline Weigh (Kg) & $65.3 \pm 6.7$ & $62.1 \pm 5.3$ & 0.16 \\
\hline Height (cm) & $156.7 \pm 4.9$ & $157.9 \pm 3.2$ & 0.26 \\
\hline Gender (M:F) & $19: 11$ & $21: 9$ & 0.58 \\
\hline $\begin{array}{c}\text { Duration of } \\
\text { Surgery (Min) }\end{array}$ & $101.58 \pm 17.7$ & $100.2 \pm 15.5$ & 0.74 \\
\hline Table 1. Baseline Characteristics of Study Participants
\end{tabular}

\begin{tabular}{|c|c|c|c|}
\hline Characteristics & Group A & Group B & $\begin{array}{c}\text { p- } \\
\text { Value }\end{array}$ \\
\hline $\begin{array}{c}\text { Time to Reach T } 10 \\
\text { Sensory Block Level }\end{array}$ & $3.2 \pm 0.35$ & $3.5 \pm 0.97$ & 0.12 \\
\hline $\begin{array}{c}\text { Time for 2 Segment } \\
\text { Sensory Regression }\end{array}$ & $112.6 \pm 8.3$ & $103.7 \pm 7.5$ & 0.0001 \\
\hline $\begin{array}{c}\text { Time Taken to Achieve } \\
\text { Complete Motor Block }\end{array}$ & $7.67 \pm 12.5$ & $8.82 \pm 3.25$ & 0.13 \\
\hline Duration of Motor Block & $155.7 \pm 16.8$ & $133.1 \pm 12.4$ & 0.0001 \\
\hline $\begin{array}{c}\text { Duration of Effective } \\
\text { Analgesia }\end{array}$ & $263.4 \pm 20.8$ & $228.7 \pm 19.8$ & 0.0001 \\
\hline $\begin{array}{c}\text { Table 2. Characteristics of Sensory and Motor Blockade } \\
\text { and Duration of Analgesia in Patients }\end{array}$ \\
\hline
\end{tabular}
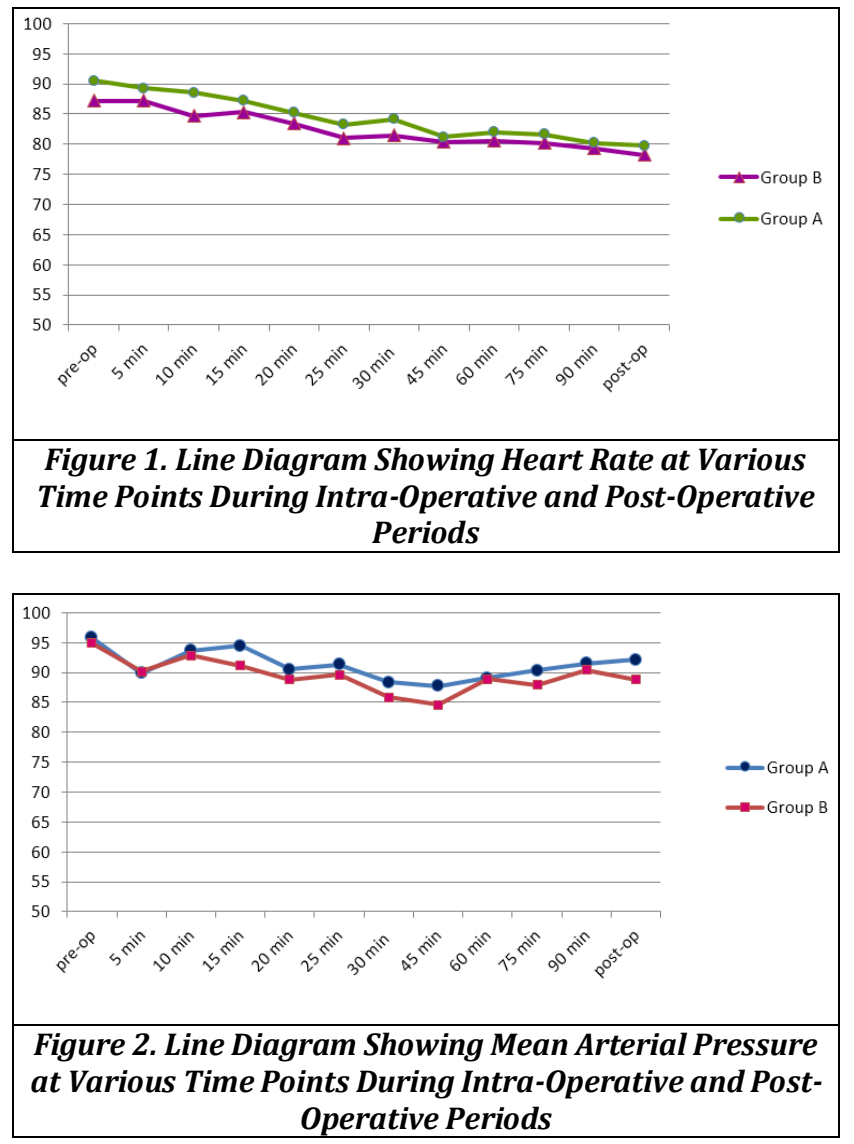

\section{DISCUSSION}

Recent trends for lower limb orthopaedic surgeries show increased acceptance of subarachnoid block. The use of adjuvants especially opioids such as fentanyl, nalbuphine with bupivacaine shown to reduce its dose requirements in spinal anaesthesia with reduced incidence of side effects and reduced dose of analgesia. The major advantage is selective blockade of pain without significant sympathetic and motor block which allows better haemodynamic stability, easy ambulation of patients and avoidance of serious side effects like cardiovascular collapse.

Bupivacaine is an amide type of local anaesthetic drug acts mainly by blockade of voltage-gated $\mathrm{Na}+$ channels in the axonal membrane and possibly has a further effect on presynaptic inhibition of calcium channels. Fentanyl primarily a mu receptor agonist with an analgesic potency greater than morphine, pethidine the analgesia produced by fentanyl is principally through interaction with mu receptor at supraspinal site. Nalbuphine hydrochloride is primarily a kappa agonist/partial mu antagonist analgesic. Kappa-opioid receptors are distributed throughout brain and spinal cord areas involved in nociception. The greatest concentrations of kappa-receptors in nociceptive regions are in lamina I and II of the spinal cord dorsal horn as well as in the spinal nucleus of the trigeminal nerve (substantia gelatinosa).

So the present randomized double-blind study was conducted to compare intrathecal nalbuphine with fentanyl as an adjuvant to $0.5 \%$ hyperbaric bupivacaine in patients undergoing lower limb orthopaedic surgery. Culebras et al. compared intrathecal morphine with intrathecal nalbuphine in different doses of $0.2 \mathrm{mg}, 0.8 \mathrm{mg}$ and $1.6 \mathrm{mg}$ and concluded that intrathecal nalbuphine $0.8 \mathrm{mg}$ provides good intraoperative and early postoperative analgesia, without 
side effects. They found that intrathecal nalbuphine $1.6 \mathrm{mg}$ did not increase the analgesic efficacy but the side effects increased in this group. ${ }^{5}$ Jyothi $\mathrm{B}$ et al. also observed that increasing nalbuphine dose from 0.8 to $1.6 \mathrm{mg}$ and $2.4 \mathrm{mg}$ did not increase analgesic efficacy. ${ }^{11}$ It implies that by increasing the dose of nalbuphine, analgesic effect increases only up to a certain point beyond which there is no further increase with the dose enhancement i.e. nalbuphine exhibits a ceiling effect to analgesia. So in the present study the dose of nalbuphine was taken as $1 \mathrm{mg}$ to compare its efficacy with fentanyl.

In the present study, it was found that onset of sensory block was comparable in the two groups as there was no significant difference between means of time to reach $\mathrm{T}_{10}$ sensory block level in two groups $(\mathrm{P}=0.12)$. Gomaa et al. compared intrathecal nalbuphine $0.8 \mathrm{mg}$ and fentanyl $25 \mu \mathrm{g}$ and found that there was no statistically significant difference in onset of sensory block between fentanyl and nalbuphine group. ${ }^{6}$ Similarly Gupta et al., 10 and Ahmed et al., 12 also found no significant difference in two groups. However, Venkata et al. found significantly faster onset of sensory block with fentanyl as adjuvant. ${ }^{13}$

We found that the mean duration of sensory block was more $(112.6 \pm 8.3 \mathrm{~min})$ in patients with nalbuphine than patients with fentanyl $(103.7 \pm 7.5 \mathrm{~min})$ and this difference was statistically significant $(\mathrm{P}<0.001)$. Gurunath et al. ${ }^{14}$ and Gupta et al. ${ }^{10}$ also observed that duration for 2 segment sensory regression in nalbuphine group was significantly prolonged as compared to fentanyl group. But Bindra et al. ${ }^{15}$ and Naaz et al. ${ }^{16}$ outlined that time of two-segment sensory regression was significantly less in patients with nalbuphine.

In the present study it was observed that the difference in the time to achieve complete motor block was not significant in two groups $(\mathrm{P}=0.13)$ though it was more in patients with fentanyl. Gupta et al.10 and Bindra et al. ${ }^{15}$ also noticed no significant difference between time for motor block in two groups. Patients with nalbuphine had prolonged duration of motor block in patients with nalbuphine $(155.7 \pm 16.8)$ than in patients with fentanyl $(133.1 \pm 12.4)$ and this was significant. Gupta et al. in their study also found similar results.

In the study we noticed that patients with nalbuphine as an adjuvant had a significantly longer duration of effective analgesia than in patients with fentanyl. The mean duration of effective analgesia in patients with nalbuphine was $263.4 \pm$ $20.8 \mathrm{~min}$ and in patients with fentanyl was $228.7 \pm 19.8 \mathrm{~min}$. The studies done by Tiwari et al. ${ }^{17}$ and Mostafa et al. ${ }^{18}$ outlined that nalbuphine had prolonged duration of analgesia than fentanyl. Gomaa et al. $^{6}$ compared postoperative analgesia between $25 \mu \mathrm{g}$ of intrathecal fentanyl with $0.8 \mathrm{mg}$ of nalbuphine and did not find any significant difference in the duration of analgesia between the two.

In the present study the mean sedation score was higher in patients with nalbuphine $(2.10 \pm 0.36)$ than in patients with fentanyl $(2.02 \pm 0.14)$ but this was not significant. Patients who received nalbuphine-bupivacaine combinations were sedated, calm, and easily arousable with verbal commands. Similarly, Naaz et al., Tiwari et al. and Mostafa et al. found sedation effect of nalbuphine. ${ }^{16-18}$

Various side effects following administration of spinal anaesthesia were minimal in both the groups. Singh et al. in his study concluded that addition of nalbuphine to intrathecal bupivacaine had prolonged the duration of sensory block and post-operative analgesia without increasing side effects or complication. ${ }^{19}$ Gurunath et al. compared intrathecal nalbuphine with fentanyl as spinal adjuvant and observed delay in onset of sensory blockade, prolonged sensory block and more duration of analgesia with minimal side effect in patients with nalbuphine as adjuvant than in patients with fentanyl. ${ }^{14}$

\section{CONCLUSION}

Nalbuphine $(1 \mathrm{mg})$ as intrathecal adjuvant to $0.5 \%$ hyperbaric bupivacaine increases the duration of sensory block, motor block and the effective analgesia time more efficiently than fentanyl in patients scheduled for elective lower limb orthopaedic surgery under subarachnoid block. So, nalbuphine may be used as an alternative to intrathecal fentanyl in these surgeries.

\section{ACKNOWLEDGEMENT}

Authors express their gratitude to all study participants for their valuable time. Authors would like to extend their gratitude to the staff associated with this study for their contribution and technical support.

\section{REFERENCES}

[1] Förster JG, Rosenberg PH. Clinically useful adjuvants in regional anaesthesia. Curr Opin Anaesthesiol 2003;16(5):477-86

[2] Bogra J, Arora N, Srivastava P. Synergistic effect of intrathecal fentanyl and bupivacaine in spinal anesthesia for cesarean section. BMC Anesthesiol 2005;5(1):5.

[3] Chu CC, Shu SS, Lin SM, et al. The effect of intrathecal bupivacaine with combined fentanyl in cesarean section. Acta Anaesthesiol Sin 1995;33(3):149-54.

[4] Mukherjee A, Pal A, Agrawal J, et al. Intrathecal nalbuphine as an adjunct to subarachnoid block: What is the most effective dose? Anesth Essays Res 2011;5(2):171-5.

[5] Culebras X, Gaggero G, Zatloukal J, et al. Advantages of intrathecal nalbuphine, compared with intrathecal morphine, after cesarean delivery: an evaluation of postoperative analgesia and adverse effects. Anesth Analg 2000;91(3):601-5.

[6] Gomaa HM, Mohamed NN, Zoheir HA, et al. A comparison between post-operative analgesia after intrathecal nalbuphine with bupivacaine and intrathecal fentanyl with bupivacaine after caesarean section. Egypt J Anaesth 2014;30(4):405-10.

[7] Yoon JY, Jee YS, Hong JY. A comparison of analgesic effects and side effect of intrathecal morphine, nalbuphine and morphine-nalbuphine mixture for pain relief during a caesarean section. Korean J Anaesthesiol 2002;42:627-33.

[8] Bromage PR. Epidural analgesia. Philadelphia: WB Saunders 1978: p. 144.

[9] Ramsay MA, Savege TM, Simpson BR, et al. Controlled sedation with alphaxalone-alphadolone. $\mathrm{Br}$ Med J 1974;2(5920):656-9. 
[10] Gupta K, Rastogi B, Gupta PK, et al. Intrathecal nalbuphine versus intrathecal fentanyl as adjuvant to $0.5 \%$ hyperbaric bupivacaine for orthopedic surgery of lower limbs under subarachnoid block: a comparative evaluation. Indian J Pain 2016;30(2):905.

[11] Jyothi B, Gowa S, Shaikh SI. A comparison of analgesic effect of different doses of intrathecal nalbuphine hydrochloride with bupivacaine and bupivacaine alone for lower abdominal and orthopedic surgeries. Indian J Pain 2014;28(1):18-23.

[12] Ahmed F, Narula $H$, Khandelwal $M$, et al. A comparative study of three different doses of nalbuphine as an adjuvant to intrathecal bupivacaine for postoperative analgesia in abdominal hysterectomy. Indian J Pain 2016;30(1):23-8.

[13] Venkata HG, Pasupuleti S, Pabba UG, et al. A randomized controlled prospective study comparing a low dose bupivacaine and fentanyl mixture to a conventional dose of hyperbaric bupivacaine for cesarean section. Saudi J Anaesth 2015;9(2):122-7.

[14] Gurunath BB, Madhusudhana R. Postoperative analgesic efficacy of intrathecal fentanyl compared to nalbuphine with bupivacaine in spinal anesthesia for lower abdominal surgeries. Anesth Essays Res 2018;12(2):535-8.
[15] Bindra TK, Kumar P, Jindal G. Postoperative analgesia with intrathecal nalbuphine versus intrathecal fentanyl in cesarean section: a double-blind randomized comparative study. Anesth Essays Res 2018;12(2):561-5.

[16] Naaz S, Shukla U, Srivastava S, et al. A comparative study of analgesic effect of intrathecal nalbuphine and fentanyl as adjuvant in lower limb orthopaedic surgery. J Clin Diagn Res 2017;11(7):UC25-8.

[17] Tiwari AK, Tomar GS, Agrawal J. Intrathecal bupivacaine in comparison with a combination of nalbuphine and bupivacaine for subarachnoid block: a randomized prospective double-blind clinical study. Am J Ther 2013;20(6):592-5.

[18] Mostafa MG, Mohamad MF, Farrag WS. Which has greater analgesic effect: intrathecal nalbuphine or intrathecal tramadol? J Am Sci 2011;7:480-4.

[19] Singh N, Kumar S, Tyagi RK. A clinical comparative study of intrathecal nalbuphine versus intrathecal fentanyl added to $0.5 \%$ hyperbaric bupivacaine for perioperative anaesthesia and analgesia in lower abdominal surgeries. IOSR J Dent Med Sci 2017;16(3):33-40. 